AFRICAN

\title{
Using the internet to teach China-Africa relations: The China-Africa Project in the seminar room
}

\author{
By Cobus van Staden \\ University of the Witwatersrand \\ Johannesburg, South Africa
}

\begin{abstract}
Compared to resource economies, geo-politics and migration, the internet has not received much attention as a factor in China-Africa relations. This is unfortunate, not only because its influence is growing larger and more complex daily, but also because it increasingly affects many other aspects shaping the relationship. In particular, the internet plays an important role in shaping the international discourse about China-Africa relations; because of online archives it also provides an opportunity to make the development of this discourse understandable to newcomers. This article is an attempt to take a first step towards analysing the value of online resources in providing African students greater insight in China-Africa relations. In particular, it will focus on one set of resources: The China-Africa Project (CAP) and its related China in Africa Podcast.
\end{abstract}

*Cobus van Staden is Lecturer in Media Studies at the University of the Witwatersrand 


\section{Introduction}

Compared to resource economies, geo-politics and migration, the internet has not received much attention as a factor in China-Africa relations. This is unfortunate, not only because its influence is growing larger and more complex daily, but also because it increasingly affects many other aspects shaping the relationship.

In particular, the internet plays an important role in shaping the international discourse about China-Africa relations; because of online archives it also provides an opportunity to make the development of this discourse understandable to newcomers. This article is an attempt to take a first step towards analysing the value of online resources in providing African students greater insight in China-Africa relations. In particular, it will focus on one set of resources: The China-Africa Project (CAP) and its related China in Africa Podcast.

The China in Africa Project is a multi-media project aimed at expanding the global conversation about China-Africa relations. This expansion happens in two ways. First, it is aimed at expanding across platforms, drawing in blogging, Facebook, Twitter, podcasting, email newsletters and mobile apps. Second, it is aimed at bridging the gap between the journalists, academics and the think tank researchers who generate China-Africa research, and the wider community. The project is particularly aimed at opening conceptual paths for undergraduate and even high school students into the conversation about China-Africa relations, while also providing a way for insiders to spread their work to a wider audience.

In writing about the uses of CAP in the classroom I am attempting to draw together my work as one of CAP's founding members, with my work as a lecturer in Media Studies at the University of the Witwatersrand, Johannesburg, South Africa. I am in the dual position of contributing to the online conversation about ChinaAfrica relations as well as drawing on internet resources to research and communicate the mediation of these relations. This article will be divided into five sections. First, I briefly contextualise China-Africa internet relations. Second, I introduce 
the China-Africa Project and lay out how the project evolved since its inception. Third, I lay out what I see as the value of CAP in introducing students to ChinaAfrica relations. Fourth, I relate how I have used CAP as a teaching resource up to now, showing how it can be integrated into various aspects of the curriculum. Finally, I point out a few limitations of the project as it currently exists and offer a few suggestions for how online resources can further contribute to deepen the global conversation about China-Africa relations.

\section{China-Africa relations and the internet}

The internet shapes China-Africa relations in many unseen ways and for that reason it also affects several issues that are currently being hotly discussed in the field. These include diplomacy, migration, governance, as well as Africa's wider ability to maximise profits from its natural resources and drive more advantageous bargains with its international partners. In addition, Chinese companies have played a key role in providing the infrastructure, telecommunication and electricity networks, and technical support upon which African internet expansion depends.

The latter is mainly affected by data network provision - a site of major investment in Africa from China. The private conglomerate Huawei and its state-owned sometimes-collaborator, sometimes-competitor ZTE are building cell phone and data networks in several African countries, including Kenya, Angola, Ethiopia and Tanzania (Clark, 2014). The impact of these companies expand beyond the construction of networks to the provision of telephony and data services, collaborating with African and international partners to tailor data services to African audiences, and providing equipment and logistical support to African mobile phone conglomerates like MTN (IT News Africa, 2014). Huawei has also launched low-cost cell phones and smartphones aimed at the African market. Chinese companies are also increasingly launching internet-based services in Africa. For example, the Chinese social media service WeChat is aggressively advertising in South Africa, a phenomenon I saw first-hand when I passed a massive WeChat display during Wits University's 2014 orientation week. In a related field, the Chinese cable television conglomerate StarTimes has also secured several contracts to implement the tran- 
sition from analogue to digital broadcasting in several African countries (Nassaka, 2014).

The width of this engagement means that Chinese internet provision also has slowly become conflated with wider controversies related to Chinese engagement with Africa as a whole, and African governments in particular. As an example, Huawei and ZTE have been accused of aiding the governments of Zimbabwe and Ethiopia in oppressive surveillance, which led to crackdowns on dissidents. ZTE also faced government investigations over allegedly flawed tender processes (Malakata, 2014).

Chinese internet provision is also accelerating wider societal change in Africa. A study I conducted with Jinghao Lu (2013) showed that Chinese social media is playing a fundamental role in Chinese migration to Africa. Chinese expatriate businesses looking for staff use Chinese-language message boards as a recruitment tool, while Chinese nationals interested in moving to Africa engage with online communities to make connections and gather advice (Lu \& Van Staden, 2013).

More pertinent to this essay, the Chinese contribution to the growth of the internet in Africa is also leading to increased political discussion, both regarding ChinaAfrica relations and the relations between publics and governments. However, in a comparative study of the political use of social media in South Africa and China, Yu-Shan Wu showed that South Africans are lagging behind Chinese in directly engaging political elites via social media. South African leaders are also slow in responding to social media pressure, unlike their Chinese counterparts ( $\mathrm{Wu}, 2013)$. However, this is not because South Africans lag behind in social media use. In 2014 I conducted an informal survey among Wits students on their total media consumption over a week. Social media was among the most used forms of media and many students indicated that social media like Twitter represent a central mechanism for maintaining relationships and keeping abreast of news. Rather, $\mathrm{Wu}$ argues that differences in political systems between South Africa and China makes social media a more central political tool for Chinese netizens.

Against the background of the complexity of China-Africa internet relations, I 
AFRICAN

AFFAIRS

believe the China Africa Project provides an interesting tool to track both how online discussions about China-Africa relations are evolving and to widen them beyond the logic of bi-lateral relations. I elaborate on this point below, but first I will briefly introduce the project.

\section{Background: The China-Africa Project}

The China-Africa project originated in 2009 as a podcast called China Talking Points, run by Eric Olander, an US American journalist who spent extensive time in China and Africa. Due to work pressure, the project lapsed. In 2011, Olander decided to revive it redesigning it slightly to focus on China's relationship with Africa. He tweeted a call for collaborators, which led to us working together to revive the podcast and expand the project across more platforms. The podcast restarted in late 2011 as a regular bi-weekly show covering three topics. From late 2012 we changed it to a weekly podcast. Listeners told us that they found a single hour-long episode covering three topics too long. We then experimented with single-topic twenty-minute episodes uploaded twice a week, which received positive feedback. The podcast is currently downloaded about 100,000 times per month, although download rates are influenced by external factors, like the podcast's placement on the iTunes page.

In 2012, we expanded the China-Africa Project to include a Facebook page ${ }^{1}$. The original aim was to create a space to engage with podcast listeners and to gather suggestions for future topics. The page quickly evolved into a news aggregator service. We post about eight to ten links to news stories about different aspects of China-Africa relations every 24 hours. These show up in members' Facebook timelines. At the time of writing (early September, 2014), the China-Africa Facebook community has about 235,000 members. The community has slowly developed into a space for discussion of China-Africa relations. Users frequently tag certain links for other members' attention, and engage each other in debates (although, as I will show below, this function is sometimes limited by the nature of social media interaction). 
We subsequently expanded the China-Africa Project across more platforms. The main addition was a dedicated website ${ }^{2}$, which features original content, as well as collecting all the podcast episodes in an easily streamable format. In addition, we also added mobile apps for Apple, Android and Blackberry smartphones, an incipient Chinese-language presence on Sina Weibo, daily updates on Twitter (under the handles@eolander and @stadenesque), and a regular email newsletter. We also added the podcast to the Stitcher and Soundcloud streaming services.

Comparing Facebook and podcast usage patterns has given us a certain level of insight into the needs of users. The Facebook page is overwhelmingly used in the developing world (especially North Africa and South Asia), while the podcast is mainly consumed in the developed world. In particular, it is downloaded in the suburbs surrounding Washington DC and in Beijing. This seems to indicate a few trends. In the first place, usage patterns seem to be shaped by the availability of bandwidth. Whereas it is easy for users in the developed world to download large sound files, their counterparts in the developing world seem to use the fact that CAP updates appear automatically in their Facebook timelines as a way to conserve clicks. In this sense, our habit of adding a brief outline of each news story might provide a useful way to skim China-Africa news without having to wait for pages to load. In the second place, legislation shapes usage patterns. The fact that Facebook is blocked in China profoundly affects the reach of the project, while the high number of downloads in Beijing indicates that Chinese internet users are interested in China-Africa relations. In the third place, CAP shows that interest in China-Africa issues extend far beyond China and Africa. In fact, in certain cases, these two are almost marginal to the conversation. In the following section I will expand on these factors in order to draw some conclusions about the project's utility as a teaching tool.

\section{CAP's potential in the seminar room}

In thinking about the use of Facebook and the wider CAP in widening students' knowledge about China-Africa issues, I drew on debates that took place over the last few years about the use of social media in teaching. However, I also distin- 


\section{AFRICAN \\ EAST-ASIAN \\ AFFAIRS

guish it from other studies that developed pedagogical methods in order to get students to focus on Facebook as an analytical object (see for example Mathison Fife, 2010) or to use Facebook as a tool for cyber-ethnography (Farquhar, 2013).

Rather than focus on Facebook as a field of study, I concentrate on its utility as a window on to a field of study - in my case, China-Africa relations. In general, I concur with Manca and Ranieri (2013) that Facebook offers three advantages as a teaching tool: it facilitates a richer mix of information resources, it brings in other sources of expertise beyond the lecturer and reading list, and it widens the context within which learning takes place.

I have found CAP a useful way to enrich my teaching about China-Africa relations for a few reasons. In the first place, because Facebook is a resource most students use on a daily basis anyway, it presents few barriers to entry. It is relatively easy for them to include it in their daily routines and presents few onerous demands (like for example creating new passwords or downloading software). It also gives students the opportunity to chart the development of China-Africa discourse in real time. They can follow conversations as they happen, while also taking note of the range of responses around a particular issue. In the third place, they can use Facebook to better understand the demographics of Facebook commenters. Because most people's Facebook data is partially public, students can get an idea of where China-Africa issues are being discussed, and this can give them an inkling of how China-Africa relations have become integrated into national political discourses in certain other countries (for example, the United States and India). The page therefore gives them ever-evolving insight into how the discussion around China-Africa relations reaches beyond China and Africa.

The page also becomes a useful resource for further research. It is a repository of links to various newspaper stories across the globe, which can also function as a sort of online database. However, we have found that Facebook sometimes does not display all the posts in a timeline, so I advise students to also keep personal repositories of particularly useful articles on resources like Instapaper. The Facebook page is also a useful place to disseminate multimedia content like interactive 
maps, video clips and infographics, as well as Soundcloud links to podcast episodes.

My main use of the CAP Facebook page is to nudge students across the gap between the issues discussed in their seminars and those playing out in their lives. In most university courses, coursework is hermetically sealed in the classroom and never seeps into everyday life. In the case of contemporary African students, their relationship with China and the rest of Asia is developing right now and it will determine their futures in fundamental ways. It is therefore crucial to get them to think about Asia-Africa relations outside of the reductive educational environment where everything relates to tests and essays. At the same time, it is essential to bring academic rigor to the wider conversation about China-Africa relations. One of the maddening aspects of following China-Africa discourse on a daily basis is realising that misinformation, myths and half-truths keep circulating in the popular press, despite having been debunked in heaps of scholarly papers. It is therefore essential to instil the rigor of academic research into students while sending them out to encounter China-Africa discourse in its raw form. The CAP Facebook community offers exactly such an opportunity.

The China in Africa podcast backs up this role, by offering students the opportunity to engage more deeply with the field. In the first place, because the podcast takes the form of a freewheeling conversation between Eric Olander, various guests and I, students can move beyond Facebook's comment/response format, where commenters frequently speak past each other and ignore each other's questions. In the second place, because our Facebook members are so young (most are under 25), we aim to provide a wide range of guests, from established academics and journalists to $\mathrm{PhD}$ students and even undergraduates. We have in the past interviewed filmmakers and journalists in their early twenties busy preparing for their first major projects or undergraduate students about their final research papers. The aim of these interviews is to give listeners an idea of the different steps one has to go through to become an established scholar, researcher or journalist. In other words, the podcast is designed to disseminate research about China-Africa relations, but also to build bridges between listeners and institutions. In both direc- 
tions, the aim is to widen the knowledge base and the conversation relating to China-Africa research. We have received feedback that teachers and lecturers have used the China-Africa Project in teaching courses on Chinese foreign policy at the University of Botswana, and in Washington DC high schools. In the following section I will describe how I have employed CAP in my own teaching.

\section{Turning clicks into learning}

My use of these resources in class is still developing, but up to now I have developed the following approach. I take the students through successive stages of engagement. At first, I make it a class requirement that all students have to join the Facebook community by 'liking' the CAP Facebook group. This will allow all the article posts to automatically appear in their personal timeline. For the first few weeks of the seminar, I require them to submit short weekly reports on the main tropes of coverage and commentary that appeared on the Facebook page that week. In certain cases I ask them to concentrate on either negative or positive coverage, or to make an argument about which particular news story would have the most significant impact on China's image in Africa that week. During this phase, we also engage with theories around soft power and public diplomacy, and I ask them to apply these theories to their arguments.

In the second phase, I instruct them to start interacting with other Facebook users. This can be through posting comments or responding to other commenters. I assign them a minimum number of such interactions per week. I monitor this activity through student feedback, while also making sure that they retain their privacy during these interactions. The aim of this exercise is to motivate them to step outside of the disengagement induced by tertiary teaching, by making them interact with real people preoccupied with these issues. I encourage them to develop more personal areas of interest within the wider field of Asia-Africa relations, in preparation for later or further postgraduate study. In addition, they can also use these interactions to expand their own knowledge about these issues.

In the final phase, I assign them the task to find and suggest new, as yet unposted, 
news stories, resources or opinion pieces relating to China-Africa relations. This phase is aimed at getting them to critically think about the nature of news sources, to hone their antennae for misinformation and to get them to explore aspects of the China-Africa relationship that have not yet been explored in existing scholarship. In each case they have to bring such stories to class, and I will then take them through the decision-making process that govern our own posting.

The course's main essay assignment draws on these previous smaller assignments, and calls on students to identify overarching tropes that define China-Africa coverage. They have to engage with debates around the concept of soft power and its relationship to media, theorize the discursive tropes' impact on Chinese soft power in relation to these debates, and finally provide suggestions about how Chinese public diplomacy might react to these tropes. The essay is designed to encourage students to think of public diplomacy as a dynamic, reactive process, rather than as a static object of study. In order to make this reality comprehensible, it is important for them to have engaged with the different currents of China-Africa discourse in real time. The CAP Facebook page offers a useful starting point for this process.

\section{Challenges and limitations}

While the China-Africa Project offers many useful teaching tools, it also faces certain limitations. While our running of the project is sometimes constrained by other professional responsibilities, travel schedules and the occasional damaged undersea internet cable, more widespread factors inherent to the internet also present challenges.

The main challenge is the legal status of Facebook in China. The fact that Facebook is blocked in China makes it harder to use it as a forum to make direct contact with people within the People's Republic of China. We have tried to compensate for this reality by commissioning regular translations of Chinese conventional and social media reactions to controversial incidents in the China-Africa sphere. These are then disseminated through the Facebook page, website and promoted via interviews with the translator on the China in Africa Podcast. However, this work 


\section{AFRICAN \\ EAST-ASIAN \\ AFFAIRS

is limited by budgets and personnel. In the future we would like to expand beyond Facebook to find a space that enables more organic interaction between Chinese and African users. These interactions are of course also limited by wider language gaps and for this reason the nature of CAP user interactions will change as more Africans learn Chinese and more Chinese learn English, Arabic, French, Portuguese and KiSwahili. We are very aware of the limitations caused by both Facebook and the current lack of a lingua franca. The first step towards further expanding the conversation about China-Africa relations is by expanding a Chinalanguage version of the project to Chinese social media. Our long-term goal is to create multiple China-Africa Project pages over various social networks in Chinese, French and Arabic, in order to communicate with more users worldwide.

The second major limitation is related to technology. According to a recent report by the Groupe Speciale Mobile Association, mobile phone subscriptions in SubSaharan Africa have increased by 18 per cent from 2007 to 2012, with 502 million SIM card connections currently active. Yet many Africans still do not have access to these technologies. GSMA estimates that 65.7 per cent of South Africans have mobile phones, while this is only true for 29.5 per cent of Nigerians and 31 per cent of Kenyans (GSMA, 2013). Even when students have nominal access to social media, mobile phone data is still expensive and slow in Africa. Many Africans are dependent on $2 \mathrm{G}$ networks, although $3 \mathrm{G}$ and $4 \mathrm{G}$ networks are expanding (thanks in no small part to Chinese conglomerates). Many Africans use prepaid data plans, and they frequently do not have access to land lines. Whereas GSMA reports 502 million SIM cards in use, only 253 million of those are mobile subscribers (GSMA, 2013). This indicates the prevalence of so-called pay-as-you-go plans in Africa, which affects both the range of data services consumed and the stability of Africans' internet access. All of this means that the number of African universities where this kind of teaching tool can be used are still limited. The only reason why I was able to make Facebook such a central part of my course was because I knew that the students have internet access on the University of the Witwatersrand's campus. This is not true for all African universities. 
A third limitation is inherent to internet communication. While many scholars have predicted that social media will expand global collaboration around pressing issues, many have also pointed out that actual usage patterns do not necessarily bear out these predictions. Internet scholars have recently come to question the very concept of online participation, pointing out that only a minority of social media users really post original content or interact with other users at all (Jenkins et al, 2013). In addition, contemporary web economies tend to blur the lines between self-expression and participation, frequently assuming that the former will lead to the latter (Jenkins \& Carpentier, 2013). In my tracking of user comments on the CAP Facebook page, I have seen similar trends. Whereas several people might comment about a particular post, they do not necessarily engage each other in conversation. Or comment on other comments. More frequently, conversations take place between page administrators and individual users, rather than between users. For this reason, I explicitly made starting such conversations a part of the students' course duties. In the process I hope that they will gain insight into some of the trends defining internet communications. This does not only include the behaviour of individual users, but also the way certain controversial issues attract the attention of activist groups who sometimes tend to repeatedly post preprepared pieces of content as if they are individual comments. Because this kind of activism occasionally manages to frame China-Africa issues [for example around Darfur and the Beijing Olympic Games in 2008 (Wu, 2012) and currently around the issue of ivory and rhino horn trade], it is important for students to see this process in action.

A fourth limitation to a comprehensive conversation about China-Africa relations might be called generational. While much of the valuable research on the reality of China-Africa relations is happening within traditional academia, the dissemination of these findings to a wider audience is hampered by the wider problems besetting academic publishing as a whole (see, for example, McCabe, 2013). In addition, unlike journalists, most academics are not necessarily encouraged to make use of social media. This culture adds to a communication gap between them and the younger generation who are experiencing the effects of China's relationship with 
AFRICAN

EAST-ASIAN

AFFAIRS

Africa on a daily basis and are enthusiastic to discuss it. As I mentioned above, the majority of CAP's members are younger than 24 and avid users of social media. Reaching them will necessitate a shift in how academics view their audiences and how academic publishing functions.

Finally, the online conversation between China and Africa is still new, and reflects the limitations of this conversation in reality. The fact is, Africans and Chinese are not yet fully communicating online because they are not fully communicating in real life. As more Chinese move to Africa and more Africans to China, and as new forms of African identity develop, new spaces for discussion and sharing will emerge online as well. This sharing is already taking place through migration, business links and academic exchange. However, more spaces are needed where Africans and Chinese can discuss shared concerns. While the China-Africa Project is still in its early stages, we hope that it will increasingly be one of these spaces, and that African students will increasingly be able to contribute to and keep track of these conversations via the China-Africa Project

\section{Conclusion}

In this paper I have outlined my attempt to use the China-Africa Project as a multimedia resource in my teaching on the concept of soft power and China-Africa engagement. While I am in the unique position of being able to use this resource while also helping to shape it, I feel that these kinds of multimedia resources could be useful in all teaching on Asia-Africa relations. For Africa to have a more fruitful engagement with Asia, Africans need spaces to enrich their knowledge of Asia. Media can provide some of these spaces. However, I would also suggest that they will become even more useful if students are trained to decode discourse and to question their own assumptions about Asia. Only if Africans can see Asia as less monolithic and more shaped by a multitude of cultures and discourses, will Africa and Asia be able to build a more permanent and constructive relationship.

\section{Endnotes}




\section{1. www.facebook.com/chinaafricaproject}

2. www.chinaafricaproject.com

\section{Bibliography}

Clark, R. 2014. Offshore Bandwidth Sparks Africa Fiber Boom [Online]. Available: http://www.lightreading.com/optical/subsea/offshore-bandwidthsparks-africa-fiber-boom/d/d-id/710689 [2014, September 12].

Farquhar, L. 2013. Performing and Interpreting Identity through Facebook Imagery. Convergence 19(4):446-471

GSMA. 2013. Sub-Saharan Africa Mobile Economy 2013 [Online]. Available: http://www.gsmamobileeconomyafrica.com/ [2014, September 12].

IT News Africa. 2014. Huawei and MTN Group ink managed services contract [Online]. Available: http://www.itnewsafrica.com/2014/09/huawei-mtngroup-ink-managed-services-contract/ [2014, September 12].

Jenkins, H., Ford, S., \& Green, J. 2013. Spreadable Media: Creating Value and Meaning in a Networked Culture. New York: New York University Press.

Jenkins, H., \& Carpentier, N. 2013. Theorising Participatory Intensities: A Conversation about Participation and Politics. Convergence 19(3):265-286.

Lu, J. \& Van Staden, C. 2013. Lonely Nights Online: How does Social Networking Channel Chinese Migration and Business to Africa, African EastAsian Affairs 1:94-116.

Malakata, M. 2014. Kenya sets up e-procurement system to fight corruption [Online]. Available: http://www.computerworld.in/news/kenya-sets-up-eprocurement-system-to-fight-corruption [2014, September 12].

Manca, S., \& Ranieri, M. 2013. Is it a tool suitable for learning? A critical review 
AFRICAN

EAST-ASIAN

AFFAIRS

of the literature on Facebook as a technology-enhanced learning environment. Journal of Computer Assisted Learning, 29:487-504.

Mathison F.J. 2010. Using Facebook to Teach Rhetorical Analysis. Pedagogy: Critical Approaches to Teaching Literature, Language, Composition and Culture, 10(3):555-562.

McCabe, B. 2013. Publish or Perish: Academic Publishing Confronts its Digital Future Johns Hopkins Magazine [Online]. Available: http://hub.jhu.edu/ magazine/2013/fall/future-of-academic-publishing [2014, September 17].

Nassaka, F. 2014. Uganda: Digital Migration at the Crossroads, The Independent [Online]. Available: http://allafrica.com/stories/201408260712.html [2014, September 12].

Wu, Y.S. 2012. The Rise of China's State-Led Media Dynasty in Africa, South African Institute of International Affairs Occasional Paper No. 117. 